\title{
Quantifying shallow subsurface water and heat dynamics using coupled hydrological-thermal-geophysical inversion
}

\author{
Anh Phuong Tran, Baptiste Dafflon, Susan S. Hubbard, Michael B. Kowalsky, Philip Long, Tetsu K. Tokunaga, and \\ Kenneth H. Williams \\ Climate \& Ecosystems Division, Earth and Environmental Sciences Area, Lawrence National Berkeley Lab, Berkeley, CA \\ 94720, USA
}

Correspondence to: Anh Phuong Tran (aptran@lbl.gov)

Received: 20 April 2016 - Published in Hydrol. Earth Syst. Sci. Discuss.: 25 April 2016

Revised: 26 July 2016 - Accepted: 17 August 2016 - Published: 31 August 2016

\begin{abstract}
Improving our ability to estimate the parameters that control water and heat fluxes in the shallow subsurface is particularly important due to their strong control on recharge, evaporation and biogeochemical processes. The objectives of this study are to develop and test a new inversion scheme to simultaneously estimate subsurface hydrological, thermal and petrophysical parameters using hydrological, thermal and electrical resistivity tomography (ERT) data. The inversion scheme - which is based on a nonisothermal, multiphase hydrological model - provides the desired subsurface property estimates in high spatiotemporal resolution. A particularly novel aspect of the inversion scheme is the explicit incorporation of the dependence of the subsurface electrical resistivity on both moisture and temperature. The scheme was applied to synthetic case studies, as well as to real datasets that were autonomously collected at a biogeochemical field study site in Rifle, Colorado. At the Rifle site, the coupled hydrological-thermal-geophysical inversion approach well predicted the matric potential, temperature and apparent resistivity with the Nash-Sutcliffe efficiency criterion greater than 0.92 . Synthetic studies found that neglecting the subsurface temperature variability, and its effect on the electrical resistivity in the hydrogeophysical inversion, may lead to an incorrect estimation of the hydrological parameters. The approach is expected to be especially useful for the increasing number of studies that are taking advantage of autonomously collected ERT and soil measurements to explore complex terrestrial system dynamics.
\end{abstract}

\section{Introduction}

Shallow subsurface moisture and temperature are two primary variables that play key roles in hydrological and biogeochemical processes in terrestrial environments. For example, watershed moisture content and temperature are the main factors that control the partitioning of precipitation into evapotranspiration, infiltration and runoff (Merz and Bardossy, 1998; Brocca et al., 2010). For ecosystems, moisture content and temperature conditions are closely linked to form, functioning and organization of vegetation, which in turn influence ecological diversity (Rodriguez-Iturbe, 2000). Subsurface moisture and temperature largely influence microbial activity in the subsurface, including respiration of greenhouse gases (Boone et al., 1998; Luo et al., 2013). However, monitoring the variability of subsurface moisture and temperature over spatiotemporal scales that are relevant to the local processes yet informative for predicting watershed or ecosystem functioning is challenging. Conventional point-sensing approaches can provide subsurface moisture and temperature. However, due to labor and costs involved in installing point-sensing systems and the invasive nature of the sensors, the spatial support scale of point-sensing systems is typically quite small compared to the scale of systems of interest.

Over the last 2 decades, many hydrogeophysical approaches have been developed to combine point and geophysical measurements for improved subsurface property estimation or process monitoring (see reviews provided by $\mathrm{Ru}-$ bin and Hubbard, 2005; Hubbard and Linde, 2011; Binley et al., 2015). Statistical approaches have been extensively used to integrate point measurements with commonly geophysical models/tomograms, such as ground-penetrating radar (GPR) 
and electrical resistance tomography (ERT). For example, Hubbard et al. (2001) applied a Bayesian algorithm to integrate surface and cross-hole GPR, seismic cross-hole tomography, cone penetrometer, borehole electromagnetic flowmeter and pumping tests to estimate the spatial distribution of subsurface hydraulic conductivity. Binley et al. (2002) estimated shallow subsurface hydraulic conductivity using both cross-well ERT and GPR. Doetsch et al. (2010) showed that merging seismic, GPR and ERT data could significantly improve the accuracy of aquifer zonation and associated zonal parameter estimation. Dafflon and Barrash (2012) used a stochastic approach to estimate the distribution of porosity from well data and GPR data. Tran et al. (2015) combined surface GPR and frequency domain reflectometry data to better quantify the spatiotemporal dynamics of moisture along a hillslope.

Coupled hydrogeophysical inversion approaches have also been developed to estimate soil hydrological parameters, which assimilate all geophysical and other key datasets into a model that consider physical hydrodynamics (i.e., Darcy's law) and electromagnetic laws (i.e., Maxwell's equations). Because coupled inversion approaches permit direct use of geophysical data for inversion, they avoid the errors typically associated with geophysical inversion process (e.g., Binley et al., 2002; Singha and Gorelick, 2005) and associated resolution issues (Day-Lewis and Lane, 2004). Kowalsky et al. (2005) and Lambot et al. (2009) developed coupled inversion schemes and used time-lapse GPR data to estimate hydraulic conductivity and matric potential functions. Johnson et al. (2009) jointly inverted time-lapse hydrogeologic and ERT data without a priori assumptions about petrophysical parameters. Using ERT data, Huisman et al. (2010) developed a coupled Bayesian hydrogeophysical inversion approach to determine the hydraulic properties and their uncertainties of flood-protection dikes. Kowalsky et al. (2011) employed time-lapse ERT, groundwater level and nitrate concentration data to estimate hydrogeochemical parameters and behavior of a contaminated subsurface system. Tran et al. (2014) developed a data assimilation scheme that is based on the maximum-likelihood ensemble filter technique to sequentially estimate the vertical soil moisture profile and parameters of water retention and hydraulic conductivity functions using full-wave GPR data.

To date, ERT is the geophysical technique that is most commonly collected in an autonomous manner for nearsurface applications. ERT provides information about the distribution of subsurface electrical resistance; a review of ERT theory and inversion procedures is given by Binley and Kemna (2005). Due to the typically high sensitivity of electrical resistivity to pore fluid conductivity and saturation, ERT has been used widely for monitoring the vadose zone soil moisture and other terrestrial system processes (e.g., Binley et al., 2002; Kemna et al., 2002; McClymont et al., 2013; Hubbard et al., 2013). However, because the electrical resistivity is also sensitive to other subsurface properties (such as porosity, tortuosity, pore-grain electrochemistry, mineralogy and temperature), other measurements must be used with ERT to avoid large estimation errors (Binley et al., 2002). For example, dependence of subsurface electrical resistivity on temperature is well known but often not adequately accounted for in hydrogeophysical approaches. The subsurface temperature directly influences the subsurface electrical resistivity. It also controls the phase change of subsurface moisture, which ultimately affects the subsurface resistivity. In some cases, subsurface temperature variations affect subsurface resistivity more than moisture variations (Rein et al., 2004; Musgrave and Binley, 2011). The conventional approach for correcting for temperature effects on ERT data includes inverting data and then performing correction on the obtained resistivity/conductivity images (Hayley et al., 2007; Ma et al., 2014). This approach is not suitable for the coupled hydrogeophysical inversion, because the objective of the hydrogeophysical inversion is to estimate hydrological parameters (not electrical resistivity/conductivity image). Hayley et al. (2010) proposed a temperature-compensation approach that removes the temperature effect on the data before inversion, which appeared to better resolve the temperature dependence of the electrical resistivity. This approach can be used for the hydrogeophysical inversion. However, this approach first requires the inversion of electrical resistance data to obtain the correction factors. Secondly, the correction usually relies on temperature measurements at several specific points in time, which may not suffice due to high variability of moisture and temperature in space and time. To date, few studies have incorporated and evaluated the effect of the relationship between subsurface resistivity and temperature within a coupled hydrogeophysical inversion scheme.

The opportunities and challenges identified above motivate the three key objectives of this study: to (1) develop a coupled hydrological-thermal-geophysical inversion scheme that is capable of incorporating nonisothermal behavior of the shallow subsurface as well as multiphase moisture into hydrogeophysical inversion and that jointly uses different thermal, hydrological and geophysical data for inversion including ERT; (2) apply the developed inversion scheme to estimate hydrological (permeability and van Genuchten curve parameters), thermal (thermal conductivity) and petrophysical parameters to assess the evaporation/infiltration processes at a Department of Energy (DOE) experimental field site in Rifle, Colorado; and (3) perform synthetic studies to explore the importance of consideration of subsurface temperature variability and its direct and indirect influence on the electrical resistivity in the hydrogeophysical inversion. To our knowledge, this is the first study that explicitly integrates both direct and indirect dependence of electrical resistivity on temperature in the coupled hydrogeophysical inversion. While it has been tested at the Rifle, CO site, we envision the new inversion approach being widely useful at other study sites, particularly those that can take advantage of autonomous ERT and other datasets. 
We organize this article as follows. Section 2 describes the development of the hydrological-thermal-geophysical inversion scheme. The application of the inversion scheme to the Rifle site study is described in Sect. 3. Section 4 compares two synthetic cases that perform geophysical inversion, with and without considering the subsurface temperature's influence. Section 5 offers a summary and concluding remarks.

\section{Methodology}

\subsection{Hydrological forward model}

In this study, we simulated the nonisothermal two-phase (gas and liquid), three-component (air, water and heat) flow in the vadose zone using the integral finite-difference simulator TOUGH2 (Transport of Unsaturated Groundwater and Heat; Pruess et al., 1999). TOUGH2 solves the mass and energy balance equations for each component over an arbitrary volume $V$, confined by a closed surface $\Gamma$ of the flow computational domain, which is written in the integral form as below:

$$
\int_{V} M^{k} d v=\int_{\Gamma} F^{k} \boldsymbol{n} d \Gamma+\int_{V} q^{k} \boldsymbol{n} d v,
$$

in which $M$ is the mass or energy accumulation term for component $k ; F$ represents the mass or heat flux; $q$ denotes the sink or source terms; and $\boldsymbol{n}$ is the normal vector on the surface element $d \Gamma$. The mass accumulation term is defined as

$M^{k}=\phi \sum_{\beta} S_{\beta} \rho_{\beta} X_{\beta}^{k}$,

where $\phi$ is the porosity; $S_{\beta}$ and $\rho_{\beta}$ are, respectively, the saturation and density of phase $\beta$; and $X_{\beta}^{k}$ is the mass fraction of phase $\beta$ in component $k$. For simulating the nonisothermal problem, the heat accumulation component $\left(M^{\mathrm{h}}\right)$ is also accounted for:

$M^{\mathrm{h}}=(1-\phi) \rho_{R} C_{R} T+\phi \sum_{\beta} S_{\beta} \rho_{\beta} u_{\beta}$,

where $\rho_{R}$ and $C_{R}$ are, respectively, the grain density and specific heat capacity of the soil/sediment particle materials; $T$ is the temperature; and $u_{\beta}$ is the specific internal energy in phase $\beta$.

The mass flux term $F^{k}$ of component $k$ is the sum of all of its phase fluxes:

$F^{k}=\sum_{\beta} f_{\beta} X_{\beta}^{k}$,

with

$f_{\beta}=-K \frac{k_{\mathrm{r} \beta}}{\mu_{\beta}} \rho_{\beta}\left(\nabla P_{\beta}-\rho_{\beta} g\right)-\phi S_{\beta}^{k} d_{\beta}^{k} \nabla X_{\beta}^{k}$.

The first term in Eq. (5) represents the advection. The second one describes the molecular diffusion. $K$ is the absolute permeability; $k_{\mathrm{r} \beta}$ is the relative permeability of phase $\beta$;
$P_{\beta}=P_{\text {ref }}+P_{\mathrm{c}}$ denotes the pressure, in which $P_{\text {ref }}$ and $P_{\mathrm{c}}$ are the reference gas pressure and matric potential; $d_{\beta}^{k}$ and $\mu_{\beta}$ are the molecular diffusion coefficient and viscosity of phase $\beta$, respectively; and $g$ is the gravitational acceleration. For gas phase (air and vapor), the diffusion coefficient is a function of pressure and temperature as

$d_{\mathrm{g}}^{k}=d_{\mathrm{g}}^{k}\left(P_{0} T_{0}\right) \frac{P_{0}}{P}\left[\frac{T+273.15}{273.15}\right]^{1.8}$,

where $d_{\mathrm{g}}^{k}\left(P_{0} T_{0}\right)$ is the gas diffusion coefficient at the standard condition $P_{0}=1 \mathrm{~atm}$, and $T_{0}=0^{\circ} \mathrm{C}$. The relationship between the matric potential, the relative permeability and the water saturation is formulated by Mulem and van Genuchten (van Genuchten, 1980) as

$P_{\mathrm{c}}=-\frac{1}{\alpha}\left(S_{\mathrm{e}}^{-1 / m}-1\right)^{1-m}$,
$k_{\mathrm{rl}}=\sqrt{S_{\mathrm{e}}}\left[1-\left(1-S_{\mathrm{e}}^{1 / m}\right)^{m}\right]^{2}$.

The relative permeability of the gas phase is described by Corey (1954) as

$k_{\mathrm{rg}}=\left\{\begin{array}{ll}(1-\hat{S})^{2}\left(1-\hat{S}^{2}\right) & \text { if } S_{\mathrm{gr}}>0 \\ 1-k_{\mathrm{rl}} & \text { if } S_{\mathrm{gr}}=0\end{array}\right.$,

where $S_{\mathrm{e}}$ and $\hat{S}$ are defined as

$S_{\mathrm{e}}=\frac{S_{\mathrm{l}}-S_{\mathrm{lr}}}{S_{\mathrm{ls}}-S_{\mathrm{lr}}}$,

$\hat{S}=\frac{S_{1}-S_{\mathrm{lr}}}{1-S_{\mathrm{lr}}-S_{\mathrm{gr}}}$,

in which $S_{\mathrm{ls}}$ represents the saturated liquid saturation; $S_{\mathrm{lr}}$ and $S_{\mathrm{gr}}$ are the residual liquid and gas saturation, respectively; $m$ represents the pore size distribution of the soil/sediment; and $\alpha$ is inversely proportional to the air-entry pressure. Heat fluxes consist of conductive and convective components:

$F^{\mathrm{h}}=-\lambda \nabla T+\sum_{\beta} h_{\beta} f_{\beta}$,

where $\lambda$ demotes the thermal conductivity and $h_{\beta}$ is the specific enthalpy in phase $\beta$. It is worth noting that the evaporation was accounted for by the diffusion term in Eq. (5). However, the current version of TOUGH 2 does not consider the root water uptake and transpiration from vegetation.

\subsection{ERT forward model}

The ERT forward model solves Poisson's equation, which describes the relationship between the potential field due to a given input current and the electrical conductivity distribution. In this study, we used the forward model of the Boundless Electrical Resistivity Tomography (BERT) package, developed by Rücker et al. (2006). BERT numerically 


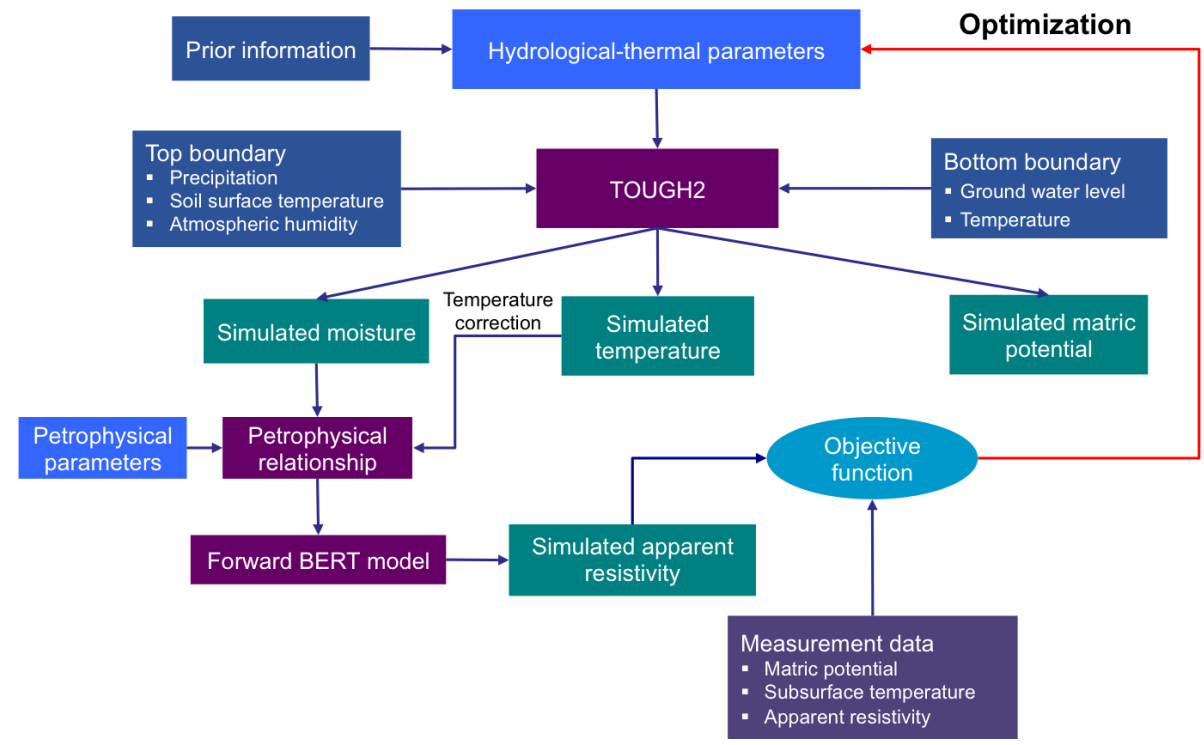

Figure 1. Flowchart showing the steps involved in the coupled hydrological-thermal-geophysical inversion scheme. The objective function is represented by Eq. (15). Estimated parameters consist of hydrological-thermal and petrophysical parameters (blue rectangles). The navy blue rectangles denote the model inputs, including prior information about estimated parameters, and the top and bottom boundary conditions. The purple rectangles denote the forward TOUGH2, geophysical and petrophysical models. The teal and indigo rectangles, respectively, denote the simulation and measurement. Data for inversion in this study include matric potential, subsurface temperature and apparent resistivity.

solves Poisson's equation using the finite-element method in a three-dimensional, arbitrary topography. By incorporating unstructured, tetrahedral meshes, the model enables efficient refinement of the local mesh, and flexibly describes any geometry of the computational domain. The use of quadratic shape functions also helps to improve the accuracy of the simulation.

\subsection{Petrophysical model}

The bulk electrical conductivity $\left(\sigma_{\mathrm{b}}\right)$ includes contributions from the electrical conductivity of pore water and the surface conduction at the pore and water-mineral interface (Revil et al., 2012). We employed the model proposed by Linde et al. (2006), which was extended from Archie's model (Archie, 1942), and is expressed below as

$\sigma_{\mathrm{b}}=\phi^{d}\left[S_{1}^{n} \sigma_{\mathrm{w}}+\left(\phi^{-d}-1\right) \sigma_{\mathrm{s}}\right]$,

where $d$ is the cementation index; $n$ is the saturation index; and $\sigma_{\mathrm{w}}$ and $\sigma_{\mathrm{s}}$ are, respectively, the electrical conductivity of water and soil/sediment surface conduction. Equation (13) indicates that the cementation and saturation indexes closely correlate. Hence, to reduce the number of unknown parameters and ameliorate nonuniqueness, we set the cementation index at $d=1.3$, which is commonly used for unconsolidated sand (Archie, 1942). The electrical conductivity of pore water, which does not vary significantly over time at the Rifle site, was taken from the measurements at the nearby well and is equal to $0.244 \mathrm{~S} \mathrm{~m}^{-1}$. In the case that the spatiotemporal variation of solute concentration and resulting electrical conductivity in pore water are significant, its dynamics should be simulated by considering it as a component in TOUGH2. A formula that links the solute concentration with the water electrical conductivity also needs to be developed.

The relationship between temperature and electrical conductivity can be formulated using linear (Sen and Goode, 1992) or exponential (Llera et al., 1990) equations. In this study, we chose the linear form:

$\sigma_{\mathrm{b}}^{T}=\sigma_{\mathrm{b}}[1+c(T-25)]$,

in which $T$ is the temperature; $\sigma_{\mathrm{b}}^{T}$ is the electrical resistivity at temperature $T^{\circ} \mathrm{C}$; and $c$ is the temperature-compensation factor, corresponding to $25^{\circ} \mathrm{C}$. The value $c=0.0183^{\circ} \mathrm{C}^{-1}$ as suggested by Hayley et al. (2007) was used for our study.

\subsection{Coupled hydrological-thermal-geophysical inversion scheme}

We developed the coupled hydrological-thermal-geophysical inversion scheme within iTOUGH2 (see Finsterle, 1999; Finsterle et al., 2012). Figure 1 presents the flowchart of the scheme, which includes seven steps: (1) simulate subsurface moisture content and temperature using the TOUGH2 model; (2) transform the simulated moisture content to an electrical conductivity image using petrophysical relationships; (3) apply the temperature correction for the electrical conductivity using the simulated temperature, and convert the corrected conductivity to a resistivity image; (4) interpolate the electrical resistivity image from the TOUGH 2 computational mesh 
to the BERT mesh; (5) execute the forward BERT model to simulate the electrical resistance from the resistivity image; (6) convert the electrical resistance to the apparent resistivity using geometric factors; and (7) minimize the misfit between simulation and measurement of the apparent resistivity and other hydrological-thermal (matric potential and temperature) data to estimate hydrological-thermal and petrophysical parameters. The misfit is formulated by the objective function as below:

$\Phi(\boldsymbol{p})=e^{T} \mathbf{C}^{-1} \boldsymbol{e}$,

where $\boldsymbol{e}=z^{*}-z(\boldsymbol{\theta}, \boldsymbol{p})$ is the residual vector quantifying the difference between the modeled $(z)$ and measured $\left(z^{*}\right)$ data; $\boldsymbol{p}$ and $\boldsymbol{\theta}$ are, respectively, the vectors representing the model parameters and input data; and $\mathbf{C}$ denotes the covariance matrix of measurements errors. We assumed that there is no correlation between measurement errors, and therefore the covariance matrix $\mathbf{C}$ becomes a diagonal matrix in which the main diagonal elements are the variances of measurement errors. It is worth noting that the vectors $z, z^{*}$ and matrix $\mathbf{C}$ can contain multiple data types. The difference in units associated with the different data types was removed by the covariance matrix of the measurement errors. For parameter estimation, we used the Levenberg-Marquardt algorithm (Marquardt, 1963) for nonlinear optimization.

The agreement between measured and modeled data was evaluated using the Nash-Sutcliffe efficiency coefficient:

$\mathrm{NSE}=1-\frac{e^{T} e}{n_{0} \sigma_{0}^{2}}$,

where $\sigma_{0}^{2}$ is the variance of the measured data and $n_{0}$ is the number of measurements. The Nash-Sutcliffe coefficient ranges from $-\infty$ to 1 . The modeled and measured data perfectly agree if this coefficient equals 1 . A coefficient of 0 implies that the model prediction is as accurate as the mean of the measured data; a value less than 0 indicates that the model prediction is worse than the measured mean.

The uncertainties of estimated parameters are characterized by their standard deviation values, which are the square root of the diagonal elements of the covariance matrix of the estimated parameters:

$\sigma_{\mathrm{p}_{i}}=\sqrt{\mathbf{C}_{\mathrm{pp}_{i i}}}$,

where $i=1, \ldots, n_{\mathrm{p}}$. The covariance matrix of the estimated parameters is computed as

$\mathbf{C}_{\mathrm{pp}}=s^{2}\left(\mathbf{J}^{T} \mathbf{C}^{-1} \mathbf{J}\right)^{-1}$,

where $\mathbf{J}$ is the Jacobian matrix and $s^{2}$ is an estimate of the error variance:

$s^{2}=\frac{e^{T} \mathbf{C}^{-1} e}{n_{0}-n_{\mathrm{p}}}$.
Good initial guesses can help to avoid local minima with unrealistic solutions. As such, we implement the following practical procedure to progressively approach an optimal solution:

1. Invert the matric potential data to obtain the subsurface hydrological parameters. In this step, we consider only the one-dimensional isothermal hydrological model.

2. Use the subsurface temperature data to estimate the thermal parameters of the one-dimensional nonisothermal hydrological model. The subsurface hydrological parameters obtained in step 1 are fixed and are used to simulate the hydrological processes.

3. Jointly invert the matric potential, temperature and apparent-resistivity data to obtain the subsurface hydrological-thermal and petrophysical parameters. The hydrological-thermal parameters from steps 1 and 2 are used as the initial guesses for this step. In this step, the inversion is performed for the two-dimensional nonisothermal hydrological model.

In each step, global sensitivity analysis is performed to evaluate the sensitivity of the calibration data with respect to the model parameters. The insensitive parameters (the sensitivity coefficient is approximately equal to 0 ) are not considered in inversion. We apply the global sensitivity analysis method referred to as one-step-at-a-time (OAT) Morris method, which is available in iTOUGH2 (Wainwright et al., 2013). This method is briefly described as follows: the parameter space of $n_{\mathrm{p}}$ parameters is normalized to the $n_{\mathrm{p}}$-dimensional domain $\left([0,1]_{\mathrm{p}}^{n}\right)$. Each dimension of this normalized domain is discretized into $n_{\mathrm{s}}-1$ equal segments, generating $n_{\mathrm{s}}$ grid points that take values in the set $\left\{0,1 /\left(n_{\mathrm{s}}-1\right), 2 /\left(n_{\mathrm{s}}-1\right), \ldots 1\right\}$. The element effect $\left(\operatorname{EE}^{j}\left(p_{i}\right)\right)$ of parameter $p_{i}$ at an arbitrary grid point with respect to model output $z$ is defined as

$\mathrm{EE}^{j}\left(p_{i}\right)=\frac{1}{F} \frac{z\left(p_{1}^{j}, \ldots, p_{i}^{j}+\Delta, \ldots, p_{n_{\mathrm{p}}}^{j}\right)-z\left(p_{1}^{j}, \ldots, p_{i}^{j}, \ldots, p_{n_{\mathrm{p}}}^{j}\right)}{\Delta},$,

in which $p^{j} \leq 1-\Delta$, with $\Delta=\frac{n_{\mathrm{s}}}{2\left(n_{\mathrm{s}}-1\right)}$, and $F$ is the scaling factor for comparing the element effects of different measurements $z$. The element effect quantifies the variation of the model output with respect to variation of parameter $p_{i}$ at a given point in the parameter space. To evaluate the parameter sensitivity, we need to calculate the element effects of all parameters at all grid points, which requires a large computing resource. To overcome this constraint, Morris (1991) generated several random sample paths and computed the element effects of each parameter along these paths. The sensitivity coefficient $|\operatorname{EE}(p i)|=\frac{1}{n_{\mathrm{s}}} \sum_{j=1}^{j=n_{\mathrm{s}}}|\operatorname{EE} j(p i)|$ determines the sensitivity of parameter $p_{i}$. A parameter with a higher sensitivity coefficient is more sensitive than the other parameters. 


\section{Field study}

\subsection{Study site and datasets}

The newly developed approach was tested at a floodplain adjoining the Colorado River, near Rifle, Colorado (USA) (Fig. 2). The perched aquifer at the site overlies lowpermeability mud and siltstones of the Eocene Wasatch Formation. Above the Wasatch Formation is a Quaternary alluvial layer consisting of sandy, gravelly unconsolidated sediments. The uppermost layer is a silty clay fill with a thickness of around $1.5-2 \mathrm{~m}$, which replaced contaminated soils and sediments removed from the site following uranium reclamation activities. Groundwater elevations fluctuate seasonally with snowmelt infiltration and Colorado River stage, and vary from around 3.5 to $2.4 \mathrm{~m}$ below ground surface.

The Berkeley Lab and others in the scientific community have performed many studies at the Rifle site to explore complex subsurface hydro-biogeochemical behavior and to test the development of new characterization and modeling approaches. For example, Li et al. (2010) used reactive transport modeling to investigate the influence of physical and geochemical heterogeneities on the spatiotemporal distribution of mineral precipitates and biomass that formed during a biostimulation experiment. Yabusaki et al. (2011) developed a three-dimensional hydro-biogeochemical reactive transport model of Rifle to improve understanding of the uranium variability, hydrological conditions and soil properties under the pulsed acetate amendment. Chen et al. (2013) developed a data-driven biogeophysical approach to quantify redoxdriven biogeochemical transformations using geochemical measurements and induced polarization data. Wainwright et al. (2015) used induced polarization data and stochastic methods to estimate the spatial distribution of naturally reduced zones in the subsurface, which served as biogeochemical hot spots; the geophysical information was used to constrain simulations of biogeochemical cycles across the Rifle floodplain. Arora et al. (2016) used reactive transport modeling approaches to explore seasonal variations in biogeochemical fluxes occurring from bedrock to canopy as well as laterally to the Colorado River. They found that $\mathrm{CO}_{2}$ concentration in the unsaturated zone could not be accurately reproduced without incorporating temperature gradients in the simulations and that incorporating temperature fluctuations resulted in an increase in the annual groundwater carbon fluxes to the river by $170 \%$. They concluded that spatial microbial and redox zonation as well as temporal fluctuations of temperature and water table depth contributed significantly to subsurface carbon fluxes in the Rifle floodplain, and they identified the need to represent temperature and moisture dynamics for accurate model simulations.

In this study, we tested our new approach using data collected along a Rifle, CO ERT transect, which includes 112 electrodes with a distance between any two adjacent electrodes of $1 \mathrm{~m}$ (Fig. 2). The ERT data were autonomously

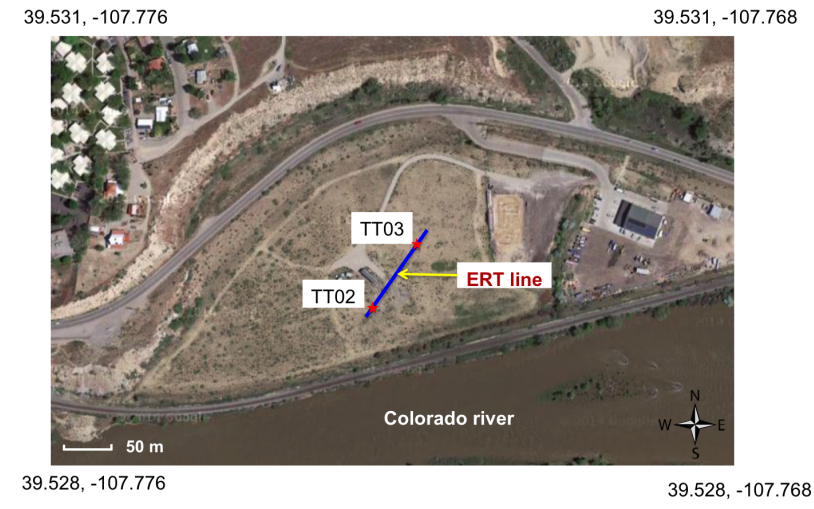

Figure 2. Plan view of the Rifle floodplain of the Colorado River, Colorado, and the location of the TT02 and TT03 wells and ERT line.

collected every day from April through June 2013 using the Wenner electrode array. These data were used for two purposes: (1) determining subsurface stratigraphy to support construction of the hydrological model and (2) estimating hydrological-thermal and petrophysical parameters through the coupled inversion approach.

For characterizing subsurface stratigraphy and specifying the depths of the fill, alluvium and Wasatch layers, we used the BERT inversion package (Günther et al., 2006) to invert the ERT data that were collected on 20 May 2013. The electrical resistivity image obtained by inversion is shown in Fig. 3a. As expected, the clay-rich fill and Wasatch layers exhibit less resistivity than the alluvium layer. To specify the locations of the fill-alluvium and alluvium-Wasatch interfaces from ERT geophysical inversion, we used the depths of these interfaces observed at the TTO2 and TTO 3 wells as the references to determine resistivity thresholds. Accordingly, a grid cell with a resistivity greater than $1.52 \log _{10}(\Omega \mathrm{m})$ and above $1.5 \mathrm{~m}$ depth belongs to the alluvium layer. The cells whose resistivity values are smaller than $1.83 \log _{10}(\Omega \mathrm{m})$ and below $5 \mathrm{~m}$ are assigned to the Wasatch layer. The remaining cells are in the fill layers. The magenta and white lines in Fig. 3 represent the fill-alluvium and alluvium-Wasatch interfaces, respectively.

We developed a computational domain that is a rectangle centered at the TT02 well, with a width of $30 \mathrm{~m}$, as shown in Fig. 3b. Previous work at this site has suggested that the spatial variability over the extent of the simulation transect is not likely to be significant ( $\mathrm{Li}$ et al., 2010). Consequently, we assumed the computational domain includes two homogeneous layers: namely, fill and alluvium. The porosity is 0.4 for the fill and 0.2 for the alluvium layer (Tetsu K. Tokunaga, personal communication, 2015). The top boundary of the domain is the atmospheric layer, and the bottom is the impermeable Wasatch layer. We set the depth of the bottom boundary at the average depth of the Wasatch layer, $z=6.5 \mathrm{~m}$. The domain was divided into 30 equally spaced 


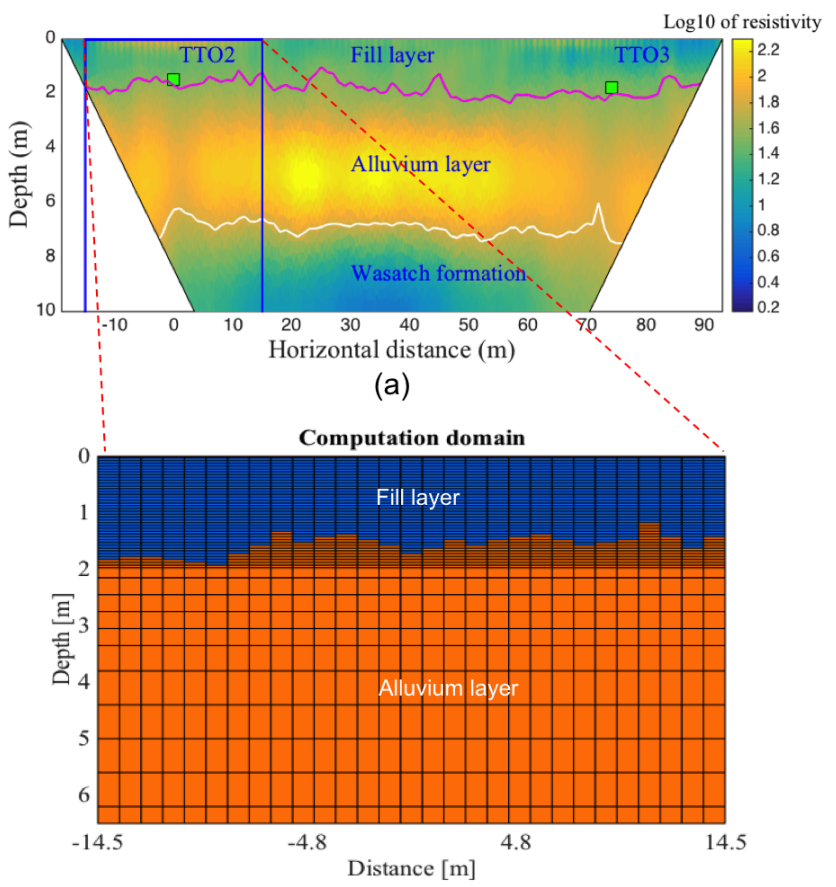

(b)

Figure 3. (a) The 2-D image of the soil electrical resistivity obtained by inverting ERT data collected on 20 May 2013. The magenta and white lines delineate the inferred fill-alluvium and alluvium-Wasatch boundaries, respectively. Green square markers denote the fill-alluvium boundary determined from the well logs of TT02 and TT03 and adjacent wells, as recorded in the field during drilling. The blue rectangular box indicates the hydrologicalthermal computational domain. (b) Computational domain for the hydrological-thermal inversion with associated grid mesh. Blue and orange regions represent the fill and alluvium layers, respectively. The domain is situated below an atmospheric layer (top boundary) and above the relatively impermeable Wasatch (bottom boundary).

columns, each with a size of $1 \mathrm{~m}$ in the horizontal direction. In the vertical direction, the cell size is $0.05 \mathrm{~m}$ for the uppermost $2 \mathrm{~mm}, 0.3 \mathrm{~m}$ for the next $1.5 \mathrm{~m}$ and $0.6 \mathrm{~m}$ for the last $3 \mathrm{~m}$, for a total of 1560 cells. The BERT computational mesh was automatically generated in BERT. We set the maximum cell size which controls the mesh refinement at a small value $(0.2 \mathrm{~m})$ to capture the local variation of the soil electrical resistivity. Other parameters that determine the BERT computational mesh were kept as their default values. For more information about BERT mesh generation, we refer to Rücker et al. (2006). The apparent resistivity was mapped from the hydrological to the BERT mesh using the nearest-distance method; i.e., a cell in the BERT mesh will get the resistivity value of its nearest cell in the hydrological mesh. The electrical resistivity of the Wasatch layer was set at its average value obtained from geophysical inversion $\left(\rho_{\mathrm{b}}^{\text {Wasatch }}=45 \Omega \mathrm{m}\right)$.

We performed the hydrological-thermal simulation during the snow-free period from 4 May 2013 to 25 November 2013 (194 days). All meteorological data (atmospheric pressure, temperature, humidity and rainfall) were measured at a nearby meteorological station. The surface boundary conditions include land surface temperature, atmospheric pressure, air mass fraction and rainfall. The land surface temperature was adjusted from the atmospheric temperature, based on a regression approach proposed by Zheng et al. (1993), while the air mass fraction was calculated from the atmospheric pressure and relative humidity data. The bottom boundary condition of pressure was calculated from the groundwater table data, and the bottom temperature was approximated from the land surface temperature. The initial conditions were derived from the measured data at the beginning of the simulation period. For more detailed information about initial and boundary conditions, we refer to Tran et al. (2016).

Data for inversion included time-lapse matric potential, temperature and apparent-resistivity measurements. Assuming that the lateral variation in subsurface temperature between TTO2 and TTO3 wells (see the TT03 location in Fig. 2) was insignificant, we used temperature data at the TTO3 well for inversion. Temperature was measured every $5 \mathrm{~min}$ at six depths below the surface: $z=0.75,1,1.5,2.5$, 4.6 and $6 \mathrm{~m}$. The $5 \mathrm{~min}$ data were averaged to obtain daily data. Using tensiometers, the matric potential was occasionally measured at the TTO2 well at depths $z=0.5,1,1.5,2$, 2.5 and $3 \mathrm{~m}$. As for the ERT data, we chose six datasets that cover the most important variations of subsurface moisture and temperature during the measurement period. For each dataset, we selected 246 values obtained from 54 electrodes in and around the computational domain for inversion. The measurement errors were assumed to follow a standard Gaussian distribution. The standard deviation of the errors for the resistivity and matric potential data are $5 \%$ of the measurement values. For the temperature data, because the instrument errors of the thermistors are from 0.1 to $0.4{ }^{\circ} \mathrm{C}$, we assumed that the standard deviation of the errors for this type of measurement is $0.4^{\circ} \mathrm{C}$.

\subsection{Results and discussion}

All of the hydrological-thermal and petrophysical parameters that were considered in this study are presented in Table 1. The first and second columns present the parameter names and ranges, respectively. From the third to the last column, we present the estimated parameters obtained from different inversion cases, namely hydrological inversion (HI), thermal inversion (TI), and coupled hydrological-thermalgeophysical inversion (HTGI).

\subsubsection{Sensitivity analysis}

The sensitivity coefficient of the matric potential data with respect to the subsurface hydrological parameters at all measured depths $(0.5,1,1.5,2,2.5,3 \mathrm{~m})$ is shown in Fig. 4a. The figure indicates that the matric potentials are more sen- 

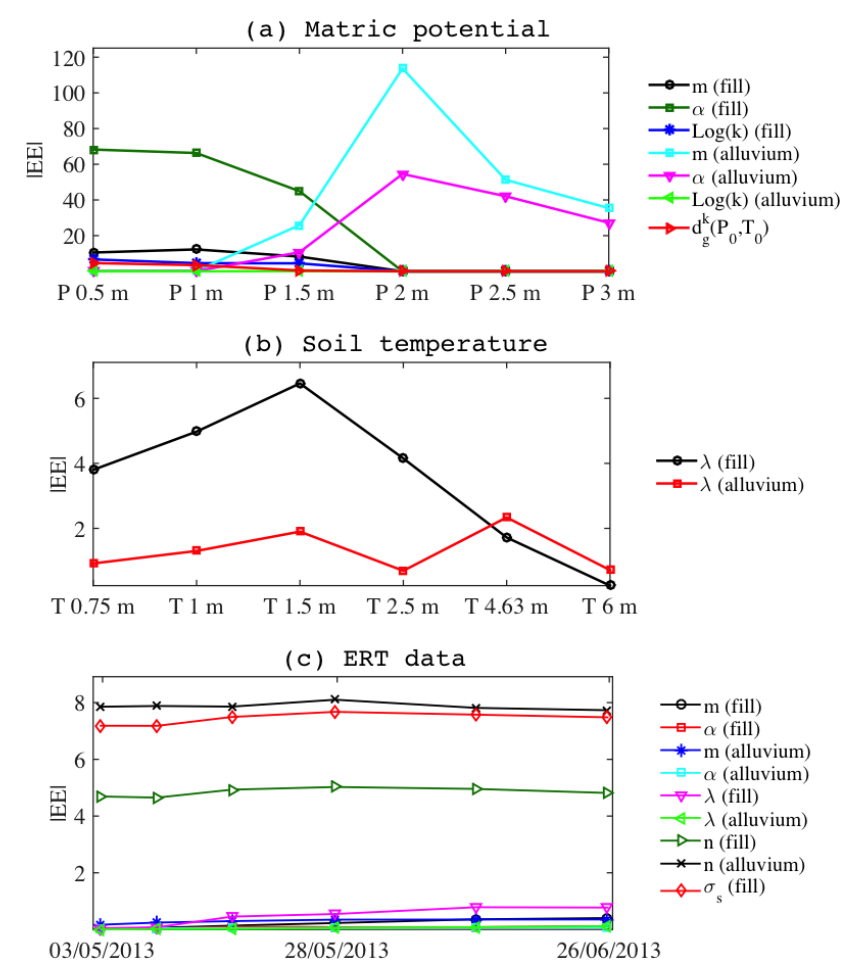

Figure 4. The sensitivity coefficients $|\mathrm{EE}|$ of matric potential, subsurface temperature and apparent-resistivity data with respect to different hydrological, thermal and petrophysical parameters. A parameter with a higher $|\mathrm{EE}|$ is more likely to be determined. (a) The sensitivity coefficient $|\mathrm{EE}|$ of the matric potential at depths of 0.5 , $1,1.5,2,2.5$ and $3 \mathrm{~m}$, with respect to the hydrological parameters of the fill and alluvium layers, and the gas diffusion coefficient standard conditions. (b) The $|\mathrm{EE}|$ of the temperature at depths of 0.75 , $1,1.5,2.5,4.63$ and $6 \mathrm{~m}$, with respect to the thermal conductivity of fill and alluvium layers. (c) The temporal variations of the $|\mathrm{EE}|$ of the resistivity data with respect to the soil hydrological-thermal and petrophysical parameters of both fill and alluvium layers.

sitive to the parameters of van Genuchten's retention curve than to the absolute permeability. At the fill layer, the influence of parameter $\alpha$ on the matric potential is significantly higher than the other parameters. The second-most-sensitive parameter is $m$. At the alluvium layer, $\alpha$ and $m$ are also the two most sensitive parameters. The sensitivity coefficient of the absolute permeability of the fill layer ( $|\mathrm{EE}|_{K_{\text {fill }}}^{\text {matric potential }}$ ) is relatively small, and that of the alluvium permeability is nearly equal to 0 . This can be explained by the lack of infiltration during the simulation period. As a result, there is little information for estimating the absolute permeability, which controls the moisture dynamics. The retention curve parameters determine the shape of the matric potential profile, and therefore the matric potential is more sensitive to them. Figure $4 \mathrm{a}$ also shows that the hydrological parameters of a given layer are mostly sensitive to the matric potential measurements at that layer. For example, the $|\mathrm{EE}|_{\alpha_{\text {fill }}}^{\text {matric potential }}$ of $\alpha$ of the fill layer on the matric potential is around 45-68 for the fill layer and 0 for the alluvium layer $(z>1.5 \mathrm{~m})$. By contrast, the $|\mathrm{EE}|_{\alpha_{\text {fill }}}^{\text {matric potential }}$ of $\alpha$ of the alluvium layer on the matric potential is 35-114 for the alluvium layer and 0 for the fill layer. This implies that there was little moisture exchange between the two layers during the simulation period.

\section{Sensitivity of temperature with thermal parameters}

The sensitivity of the subsurface temperature data with respect to the thermal conductivity of the fill and alluvium layers at depths from 0.75 to $6 \mathrm{~m}$ is depicted in Fig. 4b. The figure indicates that the sensitivity coefficient $|\mathrm{EEE}|_{\lambda_{\text {fill }}}^{\text {temperature }}$ of the thermal conductivity of the fill layer on temperature reaches its maximum at $z=1.5 \mathrm{~m}\left(|\mathrm{EE}|_{\lambda_{\text {fill }}}^{\text {temperature }}=6.5\right)$ and its minimum at $z=6 \mathrm{~m}\left(|\mathrm{EE}|_{\lambda_{\text {fill }}}^{\text {temprature }}=0.2\right)$. This implies that the temperature data at $1.5 \mathrm{~m}$ depth contain the most valuable information for estimating the thermal conductivity of the fill layer. The temperature data at depth $z=4.6 \mathrm{~m}$ are the most sensitive to the thermal conductivity of the alluvium layer $|\mathrm{EE}|_{\lambda_{\text {alluvium }}}^{\text {temperature }}=2.3$, while the temperature data at depths $0.75,2.5$ and $6 \mathrm{~m}$ are the least sensitive, with the $|\mathrm{EE}|_{\lambda_{\text {alluvium }}}^{\text {temperature }}$ roughly equal to 0.7 . The figure also indicates that the subsurface temperature data at depths $0.75,1,1.5$ and $2.5 \mathrm{~m}$ are much more sensitive to the thermal conductivity of the fill than to that of the alluvium layer. By contrast, below $2.5 \mathrm{~m}$, the sensitivity of the temperature data to the thermal conductivity of the fill layer is slightly higher than to that of the fill layer. This is because temperature at shallower depths is more dynamic in both time and space than at deeper depths. As a result, there is more information for estimating the thermal conductivity of the shallower fill layer.

\section{Sensitivity of apparent resistivity with hydrological-thermal and petrophysical parameters}

Based on the above sensitivity analysis with the matric potential and temperature data, we selected the six most sensitive hydrological-thermal parameters $(\alpha, m$ and $\lambda$, for both fill and alluvium layers) for sensitivity analysis with the apparent-resistivity data. We also considered three petrophysical parameters, including $n$ (fill, alluvium) and $\sigma_{\mathrm{s}}$ ( fill) (Eq. 13). Figure $4 \mathrm{c}$ presents the sensitivity coefficient $|\mathrm{EE}|$ of the six apparent-resistivity datasets collected at different dates with respect to nine parameters. The figure shows that the apparent-resistivity data are much more sensitive to the petrophysical parameters than to the hydrologicalthermal ones. Of the petrophysical parameters, the saturation index $(n)$ of the alluvium layer is the most sensitive parameter. Among all hydro-thermal parameters, apparent resistivity is the most sensitive to the thermal conductivity of the fill layer, implying that for this study the influence of temperature on electrical resistivity is larger than that of moisture content. The apparent-resistivity data are more sensitive to the hydrological-thermal parameters of the fill layer than 
Table 1. Constraints and estimated values of the hydrological-thermal and petrophysical parameters for different inversion cases. Hydrological inversion used matric potential data to estimate hydrological parameters ( $m$ (fill, alluvium), $\alpha$ (fill, alluvium), $K$ (fill) and $D$ ). Thermal inversion used subsurface temperature data to estimate thermal conductivity of both fill and alluvium layers $-\lambda$ (fill, alluvium). Coupled inversion used all matric potential, temperature and apparent-resistivity data to estimate parameters $m$ (fill), $\alpha$ (fill), $\lambda$ (fill), $n$ (fill), $n$ (alluvium) and $\sigma$ (fill).

\begin{tabular}{|c|c|c|c|c|}
\hline Parameter & Range & Hydrological inversion (HI) & Thermal inversion (TI) & Coupled inversion \\
\hline$m($ fill $)(-)$ & $0.4-0.6$ & $0.516( \pm 0.039,7.5 \%)$ & From HI & $0.464( \pm 0.005,1.1 \%)$ \\
\hline$\alpha($ fill $)\left(\mathrm{Pa}^{-1}\right)$ & $10^{-5}-10^{-4}$ & $2.680 \times 10^{-5}\left( \pm 2.030 \times 10^{-6}, 7.6 \%\right)$ & From HI & $3.054 \times 10^{-5}\left( \pm 3.951 \times 10^{-7}, 1.3 \%\right)$ \\
\hline$K($ fill $)\left(\mathrm{m}^{2}\right)$ & $10^{-15}-10^{-13}$ & $8.684 \times 10^{-15}\left( \pm 2.235 \times 10^{-15}, 25.7 \%\right)$ & From HI & From HI \\
\hline$m$ (alluvium) $(-)$ & $0.1-0.3$ & $0.184( \pm 0.002,1.2 \%)$ & From HI & From $\mathrm{HI}$ \\
\hline$\alpha$ (alluvium) $\left(\mathrm{Pa}^{-1}\right)$ & $10^{-4}-10^{-1}$ & $0.039( \pm 0.003,8.3 \%)$ & From HI & From HI \\
\hline$D\left(P_{0}, T_{0}\right)\left(\mathrm{m}^{2} \mathrm{~s}^{-1}\right)$ & $10^{-5}-10^{-7}$ & $7.070 \times 10^{-5}\left( \pm 2.893 \times 10^{-6}, 4.1 \%\right)$ & From HI & From HI \\
\hline$\lambda$ (fill) $\left(\mathrm{Wm}^{-1}{ }^{\circ} \mathrm{C}^{-1}\right)$ & $1.2-2.7$ & - & $2.409( \pm 0.016,0.7 \%)$ & $2.447( \pm 0.015,0.6 \%)$ \\
\hline$\lambda$ (alluvium) $\left(\mathrm{Wm}^{-1}{ }^{\circ} \mathrm{C}^{-1}\right)$ & $1.2-2.7$ & - & $1.423( \pm 0.029,2 \%)$ & From TI \\
\hline$n$ (fill) (-) & $1.3-2.5$ & - & - & $2.222( \pm 0.574,25.8 \%)$ \\
\hline$n$ (alluvium) $(-)$ & $1.3-2.5$ & - & - & $1.437( \pm 0.007,0.5 \%)$ \\
\hline$\sigma_{\mathrm{S}}($ fill $)\left(\mathrm{S} \mathrm{m}^{-1}\right)$ & $0.02-0.05$ & - & - & $0.043( \pm 0.010,22.2 \%)$ \\
\hline
\end{tabular}

$\left(P_{0}=1 \mathrm{~atm}\right.$ and $T_{0}=0^{\circ} \mathrm{C}$ ) (Eq. 6). $\lambda$ is the thermal conductivity (Eq. 12). $n$ and $\sigma_{\mathrm{s}}$ are the saturation index and soil surface conduction, respectively (Eq. 13).

those of the alluvium layer. The $|\mathrm{EE}|$ of all hydrologicalthermal parameters of the alluvium layer is mostly equal to 0 . This is because moisture and temperature exhibit larger variations in the fill than in the alluvium layer.

\subsubsection{Inversion results}

The estimated parameters and their associated uncertainties based on hydrological, thermal and coupled hydrologicalthermal-geophysical inversions are presented in Table 1. For the hydrological inversion, we used the matric potential data to estimate six hydrological parameters: $\alpha$ (both fill and alluvium), $m$ (both fill and alluvium), $K$ (fill), and $D\left(P_{0}, T_{0}\right)$. Because the matric potential data are negligibly sensitive with the permeability of the alluvium layer ( $K$ (alluvium)), we did not consider $K$ (alluvium) in hydrological inversion. We set it at $7.95 \times 10^{-12} \mathrm{~m}^{2}$, which is the value averaged from well measurements. For the thermal inversion, we estimated the thermal conductivity $(\lambda)$ of the fill and alluvium layers using temperature data. The specific heat capacity of the soil/sediment particles of both fill and alluvium layers was fixed at their typical value, $C_{R}=870 \mathrm{~kg}^{-1} \mathrm{C}^{-1}$ (Campbell and Norman, 1998). For the coupled hydrologicalthermal-geophysical inversion, we estimated six parameters including three hydrological-thermal parameters $-m$ (fill), $\alpha$ (fill) and $\lambda$ (fill) - and three petrophysical parameters, $n$ (both fill and alluvium) and $\sigma_{\mathrm{s}}$ (fill), using the matric potential, temperature and apparent-resistivity data. The surface conduction of the alluvium layer was set to 0 . Because the apparent-resistivity data show little sensitivity to the hydrological-thermal parameters of the alluvium layer, these parameters are not improved by the coupled inversion. Therefore, they were fixed at the values obtained from the hydrological and thermal inversion. The initial guesses for the fill hydrological-thermal parameters were obtained from the previous hydrological and thermal inversion.
The hydrological inversion reveals that, compared to the other hydrological parameters, the uncertainty of the absolute permeability $(K)$ of the fill layer is highest, while that of the parameter $m$ of the alluvium layer is lowest. Their standard deviation are, respectively, equal to 26 and $1 \%$ of the corresponding estimated values. It is because the matric potential data exhibit the lowest sensitivity with $K$ (fill) and the highest sensitivity with $m$ (alluvium) (see Fig. 4). Table 1 also shows that the parameters $\alpha$ and $K$ of the fill layer are small, implying that this layer has a strong water-holding capacity, and water will move downward slowly.

Results of the thermal inversion show that the uncertainties of the thermal conductivity $(\lambda)$ of both fill and alluvium layers are small. This indicates that the thermal-conductivity parameter is reliably estimated, due to the dense subsurface temperature measurements and the high sensitivity of temperature to the parameter. Table 1 also shows that the thermal conductivity of both fill and alluvium layers is relatively high, which means that the variations of the temperature at the land surface are rapidly propagated downward. The thermal conductivity of the alluvium layer is lower than that of the fill layer. This is because a large part of the alluvium layer is saturated with water and thus has much lower thermal conductivity than the drier fill layer.

The coupled inversion results are shown in the last column of Table 1. Compared to the hydrological inversion, the coupled inversion causes the parameter $m$ (fill) to fall by $10 \%$ and $\alpha$ (fill) to rise by $14 \%$. However, it is worth noting that, because parameters $\alpha$ and $m$ in the retention curve are negatively proportional, the retention curve does not change much when $m$ decreases and $\alpha$ increases. The thermal conductivity of the fill layer exhibits a negligible change. The table also indicates that, while the uncertainty of the saturation parameter $n$ (alluvium) is smaller ( $0.5 \%$ of the estimated value), the uncertainties of the parameters $n$ (fill) and $\sigma_{\mathrm{s}}$ (fill) are 
significantly large (26 and $22 \%$ of the estimated values, respectively). This can be explained by the fact that the saturation index $(n)$ and soil/sediment surface conduction $\left(\sigma_{\mathrm{s}}\right)$ closely correlate (see Eq. 13). As a result, when both of these parameters of the fill layer are concurrently estimated, their uncertainties are higher than in the case of the alluvium layer, where only the saturation index is estimated (the surface conduction of the alluvium was fixed at $\sigma_{\mathrm{s}}=0 \mathrm{~S} \mathrm{~m}^{-1}$ ).

Comparison of the measured and modeled matric potential of all eight datasets is presented in Fig. 5. The figure shows that there is good agreement between measured and modeled data, with a Nash-Sutcliffe efficiency criterion of 0.92 . We also observe that the temporal variations of the matric potential over the simulation period mostly occur at the fill layer $(z \leq 1.5 \mathrm{~m})$. When the depth is equal to or greater than $2 \mathrm{~m}$, the matric potential is nearly constant. This suggests that the moisture of the alluvium layer is less dynamic, and the variations within the fill layer do not frequently propagate to the alluvium layer during the simulation period.

The modeled and measured temperatures at depths from 0.75 to $6 \mathrm{~m}$ are shown in Fig. 6 . The figure indicates the model is capable of reproducing the spatial and temporal variations of the subsurface temperature. The Nash-Sutcliffe efficiency criterion is equal to 0.98 . The figure also shows that at the upper depths $(0.75$ and $1 \mathrm{~m})$ the model slightly underestimates the measurement. This can be explained by the errors of simplification at the land surface boundary. The heat and energy exchanges at the land surface between the atmosphere and land surface were not fully considered. Instead, the land surface temperature was approximated based on the historical data of atmospheric and land surface temperature (see the Supplement). The evaporation was represented by the upward flux from the land surface to the atmosphere. The figure also shows that the temporal variation of the measured and modeled temperature data decrease with increasing depth. For example, while the temperature at depth $z=0.75 \mathrm{~m}$ varies in a range $8-27^{\circ} \mathrm{C}$ during the simulation period, it only varies from 11 to $16^{\circ} \mathrm{C}$ at depth $z=6 \mathrm{~m}$. The peaks of the subsurface temperature appear later at deeper locations, as it takes time for heat to flow down.

The measured and modeled apparent-resistivity data on 8 May 2013 (when the modeled data were obtained through inversion) are depicted in Fig. 7a. The figure indicates that the coupled hydrological-thermal-geophysical simulation effectively reproduces the measured data. Particularly, the lateral variation of the apparent resistivity is simulated with high accuracy. Both measured and modeled data clearly indicate that the upper part of the subsurface section is more conductive (lower resistivity) than the deeper part. This is reasonable, as the deeper section contains more sand and cobbles, while the upper section contains more clayey and silty soils and therefore is more electrically conductive. Comparison of the measured and modeled resistivity data obtained from the whole simulation period is presented in Fig. 7b. The Nash-Sutcliffe efficiency criterion is equal to 0.94 . Both
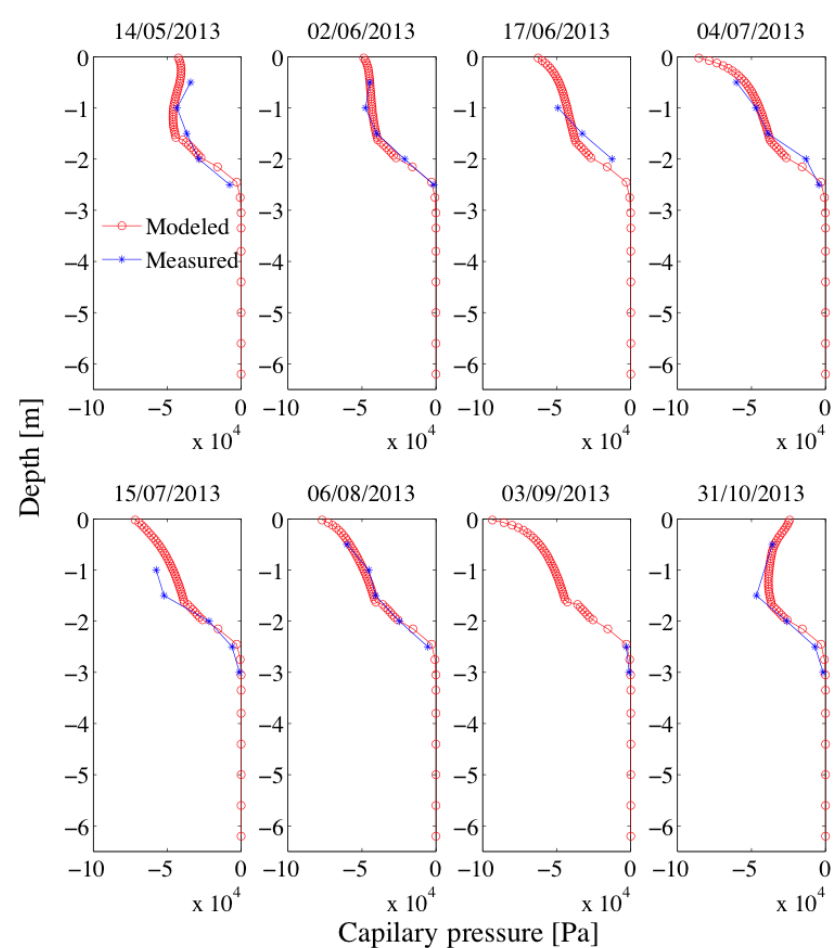

Figure 5. Comparison of the measured and modeled matric potential data for all measurement occasions. The red symbols represents the modeling results obtained from the coupled hydrologicalthermal-geophysical inversion. The blue symbols denote the measurements.

Fig. 7a and $b$ indicate that the estimation is less accurate for the high apparent-resistivity values. This can be explained by the fact that the high apparent-resistivity values are more sensitive to deeper locations and thus are harder to fit due to the influence of above soil. Another possible reason is that, with the same relative measurement error $(5 \%)$, the measurement error variances of the high resistivity values are larger than those of low resistivity values. As a result, their weights in the objective function (Eq. 15) are smaller, and they are less accurately estimated.

The water saturation and temperature versus time over the simulation period at depths $z=0.025,0.475,0.975$ and $1.525 \mathrm{~m}$ are shown in Fig. 8. For reference, the rainfall data are also presented. The figure shows that the water saturation at the surface layer rapidly responds to variations of the temperature and rainfall. It is relatively wetter at the beginning and the end of the simulation period due to high rainfall and low temperature (i.e., low evaporation), and it is drier in the middle due to low rainfall and high temperature. However, the magnitude of the variations of the water saturation quickly decreases with increasing depth. Below $z=0.475 \mathrm{~m}$, the water saturation slowly changes with time and only gradually increases with a relatively large amount of rainfall in the end of the simulation. Similar to the water saturation, the 

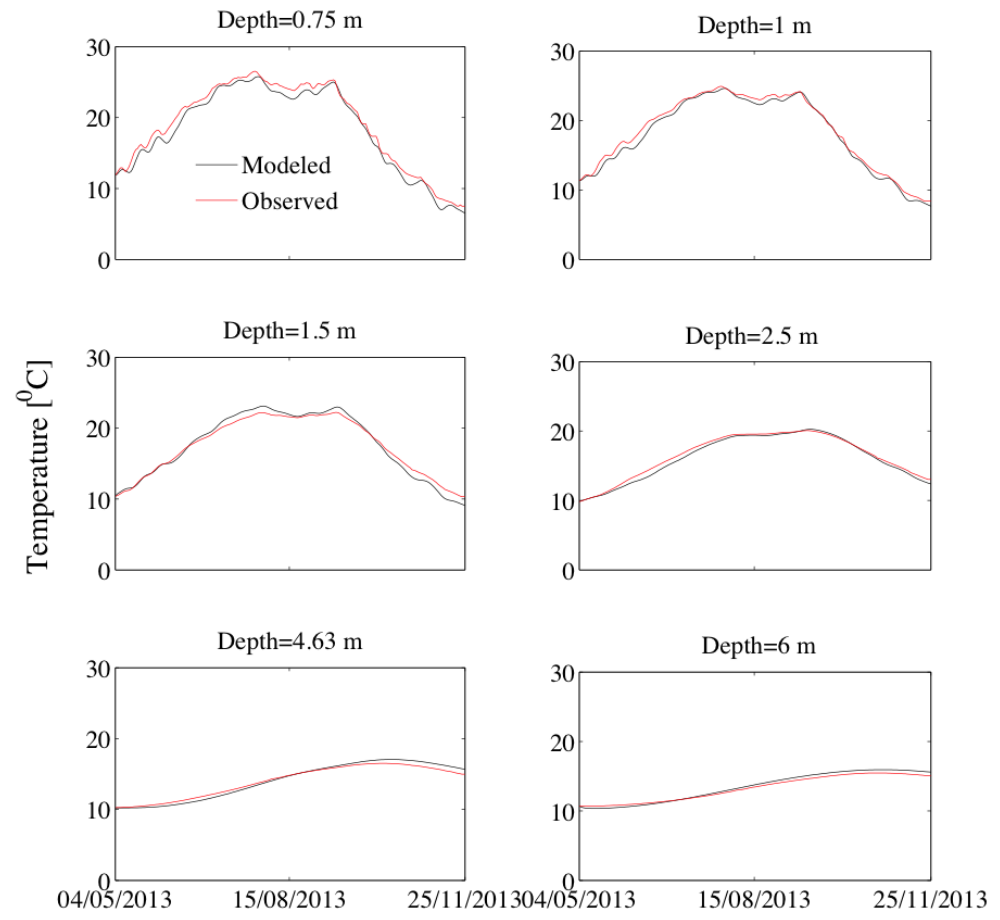

Figure 6. Comparison of the measured and modeled temperatures at depths of 0.75, 1, 1.5, 2.5, 4.63 and $6 \mathrm{~m}$ during the simulation period. The black line denotes the modeling results obtained from the coupled hydrological-thermal-geophysical inversion. The red line represents the measurements.
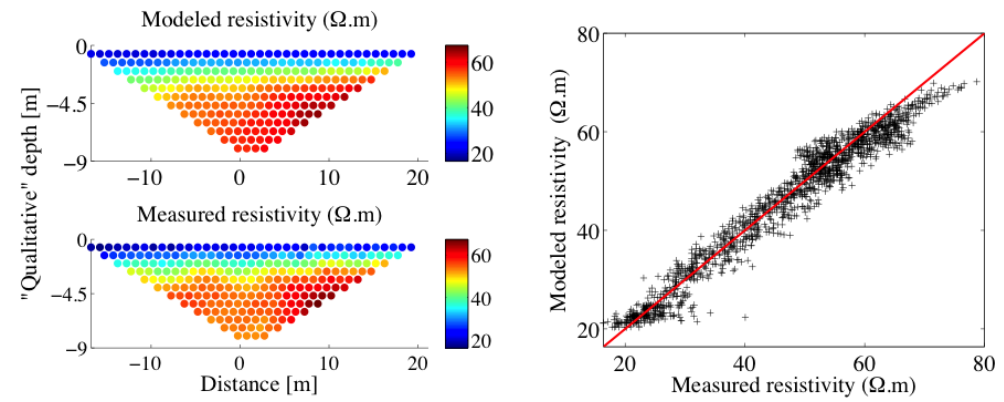

Figure 7. Left panels: an example of "quantitative" plots of the modeled and measured apparent-resistivity data on 8 May 2013. Right panel: comparison of all measured and modeled apparent-resistivity data in a 1:1 plot. The modeled data were obtained from the coupled hydrological-thermal-geophysical inversion.

subsurface temperature exhibits a high temporal variation in a range $1.8-29.8^{\circ} \mathrm{C}$ at the surface but becomes more stable at the deeper depths. At depth $z=1.525 \mathrm{~m}$, the temperature varies only from 9.6 to $22.2^{\circ} \mathrm{C}$.

The temporal variation of the water flux, which is the sum of the vapor and liquid fluxes versus time over the simulation period at depths from 0.025 to $1.525 \mathrm{~m}$, is shown in Fig. 9 . Comparing Figs. 8 and 9, we observe that the temporal variation of the water flux is highly correlated with that of the water saturation and temperature. The greatest variation occurs at $z=0.025 \mathrm{~m}$, with the flux ranging from -0.001 to $0.024 \mathrm{~m} \mathrm{day}^{-1}$. At $z=1.525 \mathrm{~m}$, the flux is constantly equal to 0 . The figure also indicates that the infiltration (positive flux values) is observed at the beginning and the end of the simulation period, when the soil is wet and rainfall occurs. At the middle of the simulation period, when the air temperature is high, the upward flux (negative flux values) occurs because of evaporation. Under the control of the diffusion, the evaporation can lead to upward flow starting at $1 \mathrm{~m}$ depth.

It is worth noting that our study assumed the Rifle subsurface was composed of two homogeneous layers, namely, fill and alluvium. For studies where the spatial heterogeneity is high, we suggest that users construct the model parameters as spatially correlated random fields characterized by variogram functions and then estimate the parameters (e.g., correlation 

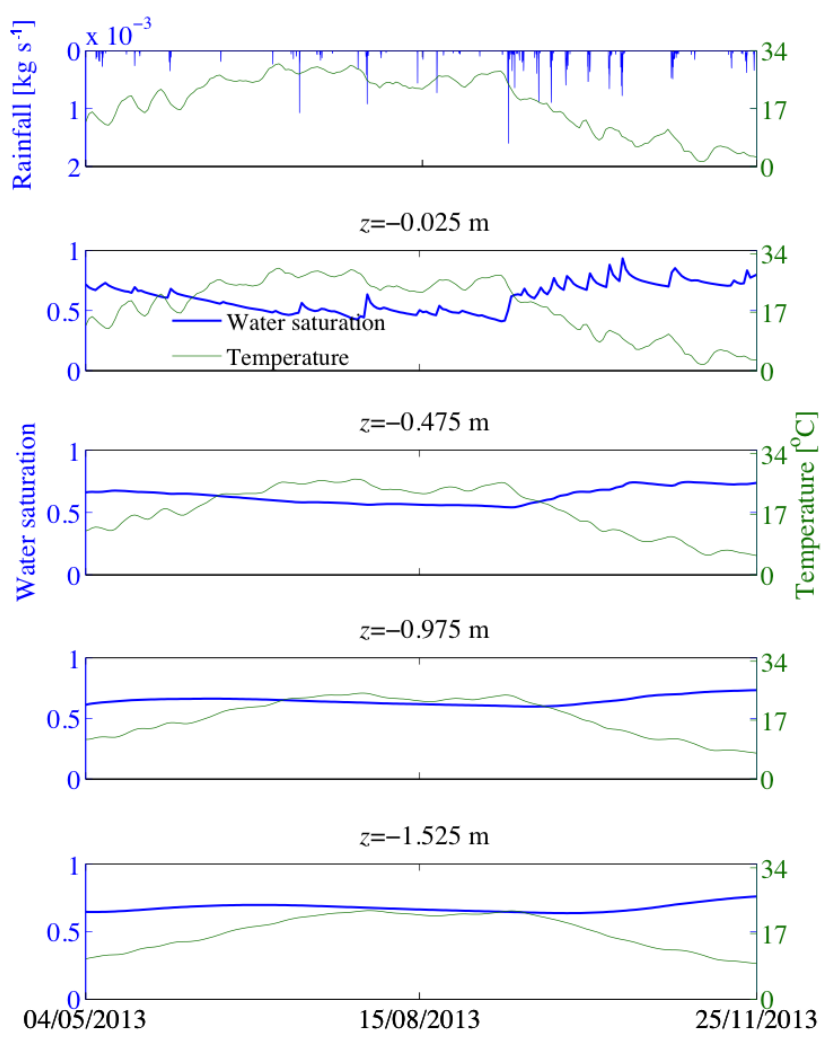

Figure 8. Temporal variation of the simulated water saturation and temperature at depths $z=0.025,0.475,0.975$ and $1.525 \mathrm{~m}$ of the TT02 well (center of the computational domain). For reference, rainfall and soil surface temperature data are also plotted.

length, anisotropy value, variance) of these variogram functions as proposed in Finsterle and Kowalsky (2007).

\section{Effect of temperature dependence of resistivity on hydrogeophysical inversion}

In this section, we consider the effects of the temperature dependence of the electrical resistivity on the estimated subsurface hydrological parameters, which are obtained by inverting apparent-resistivity data in synthetic isothermal and nonisothermal scenarios. For the isothermal scenario, the temperature was assumed to be constant in time and space at the value averaged over the whole computational domain and over the simulation period. For the nonisothermal scenario, the spatial and temporal variability of the temperature under the influences of the atmospheric temperature and hydrological-thermal parameters was fully considered. It is worth noting that the influences of temperature variability on the electrical resistivity include both direct (temperature-electrical-resistivity relationship) and indirect (via changing the hydrological-thermal processes, e.g., gasliquid phase transition) effects. The synthetic experiment was implemented as below:

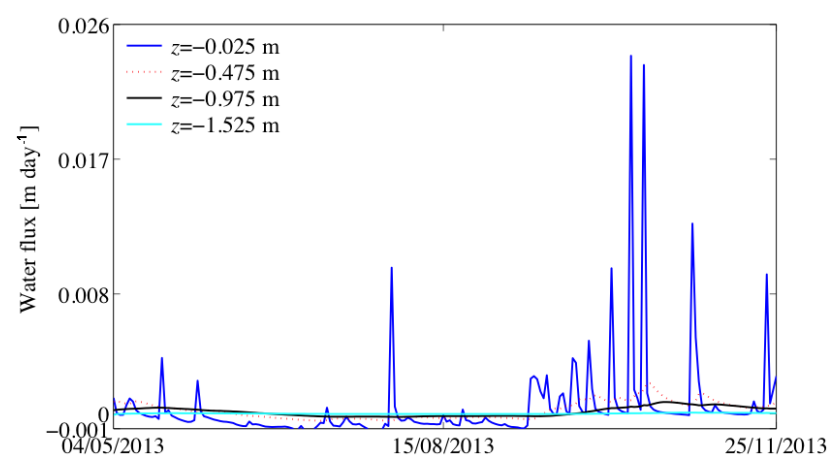

Figure 9. Temporal variation of the simulated water flux at depths $z=0.025,0.475,0.975$ and $1.525 \mathrm{~m}$ of the TT02 well. The positive and negative values indicate the downward and upward flows.

1. Run nonisothermal hydrological-thermal-geophysical forward simulation to generate artificial apparentresistivity data. Add Gaussian white noise (mean of 0 and standard deviation of $5 \%$ of artificial apparentresistivity data) to the artificial data to obtain the synthetic data.

2. Invert the synthetic apparent-resistivity data to estimate the subsurface hydrological parameters, assuming that the subsurface temperature is spatiotemporally constant (isothermal scenario).

3. Invert the synthetic apparent-resistivity data to estimate the subsurface hydrological parameters considering the nonisothermal process (nonisothermal scenario).

4. Compare inversion results of the two scenarios to evaluate the effect of the subsurface temperature variability on the hydrogeophysical inversion.

The computational domain, model parameters, and initial and boundary conditions for the synthetic forward simulation were taken from the coupled hydrological-thermalgeophysical inversion as presented in Section 3. Because the variation of the water saturation mostly occurs in the fill layer, we focused on estimating the hydrological parameters of this layer, including $\alpha, m$ and absolute permeability $K$. For both isothermal and nonisothermal scenarios, the initial guesses for the three parameters were set at $\alpha=1.8 \times 10^{-5}\left(\mathrm{~Pa}^{-1}\right), m=0.4$ and $K=4.5 \times 10^{-15} \mathrm{~m}^{2}$. To increase the sensitivity of the apparent-resistivity data with the hydrological parameters, we selected four synthetic apparent-resistivity datasets corresponding with high water saturation values. The Gaussian noise, with a mean of 0 and a relative standard deviation of $5 \%$, was added to the artificial apparent-resistivity data to generate synthetic data for the hydrogeophysical inversion.

Comparison of the synthetic van Genuchten water retention curve and the ones obtained by the isothermal and nonisothermal hydrogeophysical inversion is exhibited in 
Fig. 10a. Although the nonisothermal hydrogeophysical inversion does not perfectly estimate the synthetic parameters (due to the nonuniqueness and the correlation between parameters), its estimation is close to the synthetic ones. Meanwhile there is a large difference between the synthetic and estimated curves obtained by the isothermal hydrogeophysical scenario.

Figure $10 \mathrm{~b}$ presents the synthetic and modeled apparentresistivity data using a $1: 1$ plot. The figure shows that the nonisothermal scenario better reproduces the synthetic apparent resistivity than the isothermal does. Correlation, bias and root mean square error (RMSE) between the synthetic and simulated nonisothermal electrical resistivity data are $0.98,1$ and 2.29 , respectively, while these criteria for the isothermal scenario are 0.96, 0.98 and 3.54. In brief, ignoring temperature variability and its influence on electrical resistivity in the hydrogeophysical inversion is very likely to cause a large error for the model parameter estimation and to reduce agreement between modeled and measured geophysical data.

\section{Summary and discussion}

We developed a coupled hydrological-thermal-geophysical inversion scheme that quantifies the dependence of the electrical resistivity on both subsurface moisture and temperature, instead of solely moisture, as has been typical for previous hydrogeophysical inversion schemes. This scheme permits simulation of nonisothermal, multiphase subsurface heat and water fluxes, as well as the relationship between temperature, moisture and electrical resistivity. It accounts for the spatiotemporal variability of moisture and temperature in the shallow subsurface and can include multiple geophysical and non-geophysical measurement constraints. At present, TOUGH 2 cannot simulate the land surface processes and energy balance at the land surface. To mitigate this disadvantage, this study approximated the top land surface temperature boundary condition from the atmospheric temperature using a regression approach. The evaporation was considered via the gas phase of moisture. The evaporation rate was simulated as the water vapor fluxes moving upward from the top layer to the atmosphere.

The new approach was applied to data collected at a field site in Rifle, Colorado. The ERT data were used to characterize subsurface stratigraphy and to constrain the computational domain for the hydrological-thermal model. The time-lapse ERT data were used with other hydrological and thermal data to constrain the inversion. The inversion results show that our developed scheme well reproduces the matric potential, temperature and apparent-resistivity data. The obtained results indicate that the temporal variation of the moisture mostly occurs at the overlying fill layer, due to the relatively small amount of rainfall and the high water-holding capacity of this layer. The alluvium moisture exhibits a minimal change. Both fill and alluvium layers have high thermal (a)
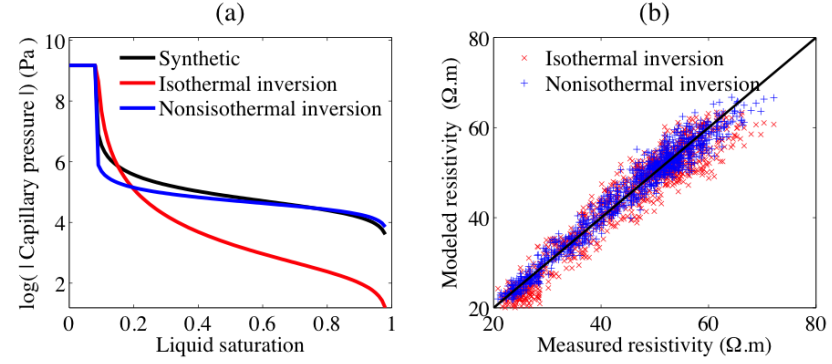

Figure 10. (a) Comparison of the synthetic and estimated van Genuchten's retention curve. (b) Comparison of synthetic and modeled apparent-resistivity data. The red color represents the results obtained by the isothermal hydrogeophysical inversion scenarios. The blue color denotes the nonisothermal scenario.

diffusivities, permitting the variation of the air temperature to rapidly move down. The obtained results also indicate that the thermal-conductivity and van Genuchten parameters of both fill and alluvium layers are well estimated with low uncertainties. However, due to limited temporal variations of moisture content (and thus ERT data), it is difficult to obtain the absolute permeability of the fill layer and the petrophysical parameters.

To evaluate the influence of the temperature dependence of the electrical resistivity on the estimation of the hydrological parameters in the hydrogeophysical inversion, we performed a synthetic study. By comparing the results obtained from the isothermal and nonisothermal scenarios, we determined that ignoring the spatial and temporal variability of the subsurface temperature may cause errors in the estimation of hydrological parameters.

Our study documents the value of accounting for the dependence of both moisture content and temperature on electrical resistivity within a hydrological-thermal-geophysical inversion framework. The inversion scheme presented here can be widely applied to many studies striving to quantify hydrological and thermal dynamics in the subsurface. We believe that this and other approaches (e.g., Kalman ensemble filter, maximum likelihood ensemble filter, particle filter) that permit rapid assimilation of autonomous monitoring datasets will greatly improve our understanding of terrestrial system properties and their behavior, including their response to environmental perturbations such as floods and droughts.

\section{Data availability}

Both the data and input files necessary to reproduce the studies are available from the authors upon request (aptran@lbl.gov).

Acknowledgements. This material is based upon work supported as part of the Sub-surface Science Scientific Focus Area funded by the US Department of Energy, Office of Science, Office of Biological 
and Environmental Research under award number DE-AC0205CH11231. The authors would like to thank Stefan Finsterle for providing iTOUGH2 codes and support, and Thomas Günther for providing the BERT codes.

Edited by: N. Romano

Reviewed by: N. Linde and J. Boaga

\section{References}

Archie, G. E.: The electrical resistivity log as an aid in determining some reservoir characteristics, Petrol. Trans. AIME, 146, 54-62, 1942.

Arora, B., Spycher, N. F., Steefel, C. I., Molins, S., Bill, M., Conrad, M. E., Dong, W., Faybishenko, B., Tokunaga, T. K., Wan, J., and Williams, K. H.: Influence of hydrological, biogeochemical and temperature transients on subsurface carbon fluxes in a flood plain environment, Biogeochemistry, 127, 367-396, 2016.

Binley, A. and Kemna, A.: Dc resistivity and induced polarization methods, in: Hydrogeophysics, Water Science and Technology Library, vol. 50, edited by: Rubin, Y. and Hubbard, S., Springer Netherlands, 129-156, 2005.

Binley, A., Cassiani, G., Middleton, R., and Winship, P.: Vadose zone flow model parameterisation using cross-borehole radar and resistivity imaging, J. Hydrol., 267, 147-159, doi:10.1016/S0022-1694(02)00146-4, 2002.

Binley, A., Hubbard, S. S., Huisman, J. A., Revil, A., Robinson, D. A., Singha, K., and Slater, L. D.: The emergence of hydrogeophysics for improved understanding of subsurface processes over multiple scales, Water Resour. Res., 51, 3837-3866, 2015.

Boone, R. D., Nadelhoffer, K. J., Canary, J. D., and Kaye, J. P.: Roots exert a strong influence on the temperature sensitivity of soil respiration, Nature, 396, 570-572, doi:10.1038/25119, 1998.

Brocca, L., Melone, F., Moramarco, T., Wagner, W., Naeimi, V., Bartalis, Z., and Hasenauer, S.: Improving runoff prediction through the assimilation of the ASCAT soil moisture product, Hydrol. Earth Syst. Sci., 14, 1881-1893, doi:10.5194/hess-141881-2010, 2010.

Campbell, G. S. and Norman, J. M.: An introduction to environmental biophysics, Springer Science \& Business Media, New York, USA, 1998.

Chen, J., Hubbard, S. S., and Williams, K. H.: Data-driven approach to identify field-scale biogeochemical transitions using geochemical and geophysical data and hidden Markov models: Development and application at a uranium-contaminated aquifer, Water Resour. Res., 49, 6412-6424, 2013.

Corey, A. T.: The interrelation between gas and oil relative permeabilities, Producers Monthly, 19, 38-41, 1954.

Dafflon, B. and Barrash, W.: Three-dimensional stochastic estimation of porosity distribution: Benefits of using groundpenetrating radar velocity tomograms in simulated-annealingbased or Bayesian sequential simulation approaches, Water Resour. Res., 48, W05553, doi:10.1029/2011WR010916, 2012.

Day-Lewis, F. D. and Lane, J. W.: Assessing the resolutiondependent utility of tomograms for geostatistics, Geophys. Res. Lett., 31, L07503, doi:10.1029/2004GL019617, 2004.

Doetsch, J., Linde, N., Coscia, I., Greenhalgh, S. A., and Green, A. G.: Zonation for 3D aquifer characterization based on joint inver- sions of multimethod crosshole geophysical data, Geophysics, 75, G53-G64, doi:10.1190/1.3496476, 2010.

Finsterle, S.: iTOUGH2 User's Guide, Lawrence Berkeley National Laboratory, Berkeley, CA, 1999.

Finsterle, S. and Kowalsky, M. B.: iTOUGH2-GSLIB user's guide, Technical report, Lawrence Berkeley National Laboratory, Berkeley, USA, 2007.

Finsterle, S., Kowalsky, M., and Pruess, K.: TOUGH: Model use, calibration and validation, T. ASABE, 55, 1275-1290, 2012.

Günther, T., Rücker, C., and Spitzer, K.: Three-dimensional modelling and inversion of dc resistivity data incorporating topography - II. Inversion, Geophys. J. Int., 166, 506-517, doi:10.1111/j.1365-246X.2006.03011.x, 2006.

Hayley, K., Bentley, L. R., Gharibi, M., and Nightingale, M.: Low temperature dependence of electrical resistivity: Implications for near surface geophysical monitoring, Geophys. Res. Lett., 34, L18402, doi:10.1029/2007GL031124, 2007.

Hayley, K., Bentley, L., and Pidlisecky, A.: Compensating for temperature variations in time-lapse electrical resistivity difference imaging, Geophysics, 75, WA51-WA59, 2010.

Hubbard, S. S. and Linde, N.: Hydrogeophysics, in: Chapter 43, Treatise on Water, edited by: Wilderer, P., Elsevier, Amsterdam, the Netherlands, 2011.

Hubbard, S. S., Chen, J., Peterson, J., Majer, E. L., Williams, K. H., Swift, D. J., Mailloux, B., and Rubin, Y.: Hydrogeological characterization of the south oyster bacterial transport site using geophysical data, Water Resour. Res., 37, 2431-2456, doi:10.1029/2001WR000279, 2001.

Hubbard, S. S., Gangodagamage, C., Dafflon, B., Wainwright, H., Peterson, J., Gusmeroli, A., Ulrich, C., Wu, Y., Wilson, C., Rowland, J. and Tweedie, C.: Quantifying and relating land-surface and subsurface variability in permafrost environments using Lidar and surface geophysical datasets, Hydrogeol. J., 21, 149-169, 2013.

Huisman, J., Rings, J., Vrugt, J., Sorg, J., and Vereecken, H.: Hydraulic properties of a model dike from coupled Bayesian and multi-criteria hydrogeophysical inversion, J. Hydrol., 380, 6273, doi:10.1016/j.jhydrol.2009.10.023, 2010.

Johnson, T. C., Versteeg, R. J., Huang, H., and Routh, P. S.: Datadomain correlation approach for joint hydrogeologic inversion of time-lapse hydrogeologic and geophysical data, Geophysics, 74, F127-F140, 2009.

Kemna, A., Vanderborght, J., Kulessa, B., and Vereecken, H.: Imaging and characterisation of subsurface solute transport using electrical resistivity tomography (ERT) and equivalent transport models, J. Hydrol., 267, 125-146, 2002.

Kowalsky, M. B., Finsterle, S., Peterson, J., Hubbard, S. S., Rubin, Y., Majer, E., Ward, A., and Gee, G.: Estimation of field-scale soil hydraulic and dielectric parameters through joint inversion of GPR and hydrological data, Water Resour. Res., 41, W11425, doi:10.1029/2005WR004237, 2005.

Kowalsky, M. B., Gasperikova, E., Finsterle, S., Watson, D., Baker, G., and Hubbard, S. S.: Coupled modeling of hydrogeochemical and electrical resistivity data for exploring the impact of recharge on subsurface contamination, Water Resour. Res., 47, W02509, doi:10.1029/2009WR008947, 2011.

Lambot, S., Slob, E. C., Rhebergen, J., Lopera, O., Jadoon, K. Z., and Vereecken, H.: Remote estimation of the hydraulic properties of a sand using full-waveform integrated hydrogeophysical 
inversion of time-Lapse, off-ground GPR data, Vadose Zone J., 8, 743-754, 2009.

Li, L., Steefel, C. I., Kowalsky, M. B., Englert, A., and Hubbard, S. S.: Effects of physical and geochemical heterogeneities on mineral transformation and biomass accumulation during biostimulation experiments at Rifle, Colorado, J. Contam. Hydrol., 112, 45-63, 2010.

Linde, N., Binley, A., Tryggvason, A., Pedersen, L. B., and Revil, A.: Improved hydrogeophysical characterization using joint inversion of cross-hole electrical resistance and groundpenetrating radar traveltime data, Water Resour. Res., 42, W12404, doi:10.1029/2006WR005131, 2016.

Llera, F. J., Sato, M., Nakatsuka, K., and Yokoyama, H.: Temperature dependence of the electrical resistivity of water-saturated rocks, Geophysics, 55, 576-585, doi:10.1190/1.1442869, 1990.

Luo, G. J., Kiese, R., Wolf, B., and Butterbach-Bahl, K.: Effects of soil temperature and moisture on methane uptake and nitrous oxide emissions across three different ecosystem types, Biogeosciences, 10, 3205-3219, doi:10.5194/bg-10-3205-2013, 2013.

Ma, Y., Van Dam, R. L., and Jayawickreme, D. H.: Soil moisture variability in a temperate deciduous forest: insights from electrical resistivity and throughfall data, Environ. Earth Sci., 72, $1367-$ 1381, doi:10.1007/s12665-014-3362-y, 2014.

Marquardt, D. W.: An algorithm for least-squares estimation of nonlinear parameters, J. Soc. Indust. Appl. Math., 11, 431-441, 1963.

McClymont, A. F., Hayashi, M., Bentley, L. R., and Christensen, B. S.: Geophysical imaging and thermal modeling of subsurface morphology and thaw evolution of discontinuous permafrost, J. Geophys. Res.-Ea. Surf., 118, 1826-1837, doi:10.1002/jgrf.20114, 2013.

Merz, B. and Bardossy, A.: Effect of spatial variability on the rainfall runoff process in a small loess catchment, J. Hydrol., 212, 304-317, 1998 .

Morris, M. D.: Factorial sampling plans for preliminary computational experiments, Technometrics, 33, 161-174, doi:10.1080/00401706.1991.10484804, 1991.

Musgrave, H. and Binley, A.: Revealing the temporal dynamics of subsurface temperature in a wetland using time-lapse geophysics, J. Hydrol., 396, 258-266, doi:10.1016/j.jhydrol.2010.11.008, 2011.

Pruess, K., Oldenburg, C., and Moridis, G.: TOUGH2 user's guide, version 2.0, Lawrence Berkeley National Laboratory, Berkeley, CA, 1999.

Rein, A., Hoffmann, R., and Dietrich, P.: Influence of natural time-dependent variations of electrical conductivity on DC resistivity measurements, J. Hydrol., 285, 215-232, doi:10.1016/j.jhydrol.2003.08.015, 2004.

Revil, A., Karaoulis, M., Johnson, T., and Kemna, A.: Review: Some low-frequency electrical methods for subsurface characterization and monitoring in hydrogeology, Hydrogeol. J., 20, 617658, doi:10.1007/s10040-011-0819-x, 2012.
Rodriguez-Iturbe, I.: Ecohydrology: A hydrologic perspective of climate-soil-vegetation dynamics, Water Resour. Res., 36, 3-9, doi:10.1029/1999WR900210, 2000.

Rubin, Y. and Hubbard, S. S.: Hydrogeophysics, vol. 50, Springer, the Netherlands, 2005.

Rücker, C., Gunther, T., and Spitzer, K.: Three-dimensional modelling and inversion of DC resistivity data incorporating topography - I. modelling, Geophys. J. Int., 166, 495-505, doi:10.1111/j.1365-246X.2006.03010.x, 2006.

Sen, P. and Goode, P.: Influence of temperature on electrical conductivity on shaly sands, Geophysics, 57, 89-96, doi:10.1190/1.1443191, 1992.

Singha, K. and Gorelick, S. M.: Saline tracer visualized with three-dimensional electrical resistivity tomography: Field-scale spatial moment analysis, Water Resour. Res., 41, W05023, doi:10.1029/2004WR003460, 2005.

Tran, A. P., Vanclooster, M., Zupanski, M., and Lambot, S.: Joint estimation of soil moisture profile and hydraulic parameters by ground-penetrating radar data assimilation with maximum likelihood ensemble filter, Water Resour. Res., 50, 3131-3146, doi:10.1002/2013WR014583, 2014.

Tran, A. P., Bogaert, P., Wiaux, F., Vanclooster, M., and Lambot, S.: High-resolution space-time quantification of soil moisture along a hillslope using joint analysis of ground penetrating radar and frequency domain reflectometry data, J. Hydrol., 523, 252-261, 2015.

Tran, A. P., Dafflon, B., and Hubbard, S.: iMatTOUGH: An open-source Matlab-based graphical user interface for pre- and post-processing of TOUGH2 and iTOUGH2 models, Comput. Geosci., 89, 132-143, doi:10.1016/j.cageo.2016.02.006, 2016.

van Genuchten, M. T.: A closed-form equation for predicting the hydraulic conductivity of unsaturated soils, Soil Sci. Soc. Am. J., 44, 892-898, 1980.

Wainwright, H. M., Finsterle, S., Jung, Y., Zhou, Q., and Birkholzer, J. T.: Making sense of global sensitivity analyses, Comput. Geosci., 65, 84-94, doi:10.1016/j.cageo.2013.06.006, 2013.

Wainwright, H. M., Orozco, A. F., Bücker, M., Dafflon, B., Chen, J., Hubbard, S. S., and Williams, K. H.: Hierarchical Bayesian method for mapping biogeochemical hot spots using induced polarization imaging, Water Resour. Res., 52, 533-551, doi:10.1002/2015WR017763, 2015.

Yabusaki, S. B., Fang, Y., Williams, K. H., Murray, C. J., Ward, A. L., Dayvault, R. D., Waichler, S. R., Newcomer, D. R., Spane, F. A., and Long, P. E.: Variably saturated flow and multicomponent biogeochemical reactive transport modeling of a uranium bioremediation field experiment, J. Contam. Hydrol., 126, 271-290, 2011.

Zheng, D., Hunt, J. E. R., and Running, S. W.: A daily soil temperature model based on air temperature and precipitation for continental applications, Clim. Res., 2, 183-191, 1993. 